\title{
The COSMIC DUST ANALYZER for the CASSINI Mission to Saturn
}

\author{
R. Srama, E. Grün, The CASSIN1-Dust-Science Team \\ Max-Planck-Institut für Kernphysik, Postf. 103980, 69029 Heidelberg, \\ Germany
}

\begin{abstract}
In October 1997 a unique mission to the Saturnian system will be launched by NASA, the CASSINI mission. One goal of this mission is to study the Saturnian dust environment, and for this task, the COSMHC DUST ANALYZFR (CDA) has been developed and is currently being tested. Impact ionization is used to determine the speed $(1-100$ $\mathrm{km} / \mathrm{s})$ and the mass $\left(1 \cdot 10^{-15}-1 \cdot 10^{-9} \mathrm{~g}\right)$ of impinging particles. Fur. thermore, the electric charge $\left(1 \cdot 10^{-15}-1 \cdot 10^{-12} \mathrm{C}\right)$ of the particles can be measured via the induction principle, and an integrated time-of-flight mass spectrometer will analyze the chemical composition of individual dust particles. Ir order to achieve sufficient sensitivity for dust fluxes as low as 10 particles/(Inonth $\mathrm{m}^{2}$ ), the sensor has a large sensitive area of $0.1 \mathrm{~m}^{2}$. This paper will describe the function of the experiment.
\end{abstract}

\section{Introduction}

The Cosmic Dust Analyzer (CDA) for the Cassini mission will be manufactured and managed by the Max-Planck-Institut für Kernphysik in Germany. The experiment weighs $16 \mathrm{~kg}$ and consumes 12 Watts. The contributions for this international project are listed in Ratcliff et al. (1992) and Fig. 1. The scientific objectives during the long operation time are diverse (Grün (1989)) : During the interplanetary cruise, the interest is dedicated to the planetary, interstellar and cometary dust, its dynamics and characteristics such as mass, velocity, electric charge and chemical composition. Especially the results from the presently active Galileo and Ulysses missions can be verified, and new and more detailed data can be obtained of the interstellar dust discovered by the Ulysses dust. experiment. Although the main scientific objectives relate to the interesting aspects of the Saturnian dust environment, Cassini's flyby at Jupiter car be used to study variable dust phenomena that complement the nominal Galileo Mission.

\section{General Experiment Description}

The CDA development was based on the experience of the successfully operating GALDLO and ULYSSES dust detectors (Grün et al. (1992a), Grün et al. (1992b)). In principle, the experiment consists of two standalone instruments (F'ig. 1): the Dust Analyser (DA) and the High Rate Detector (HRD), which is 

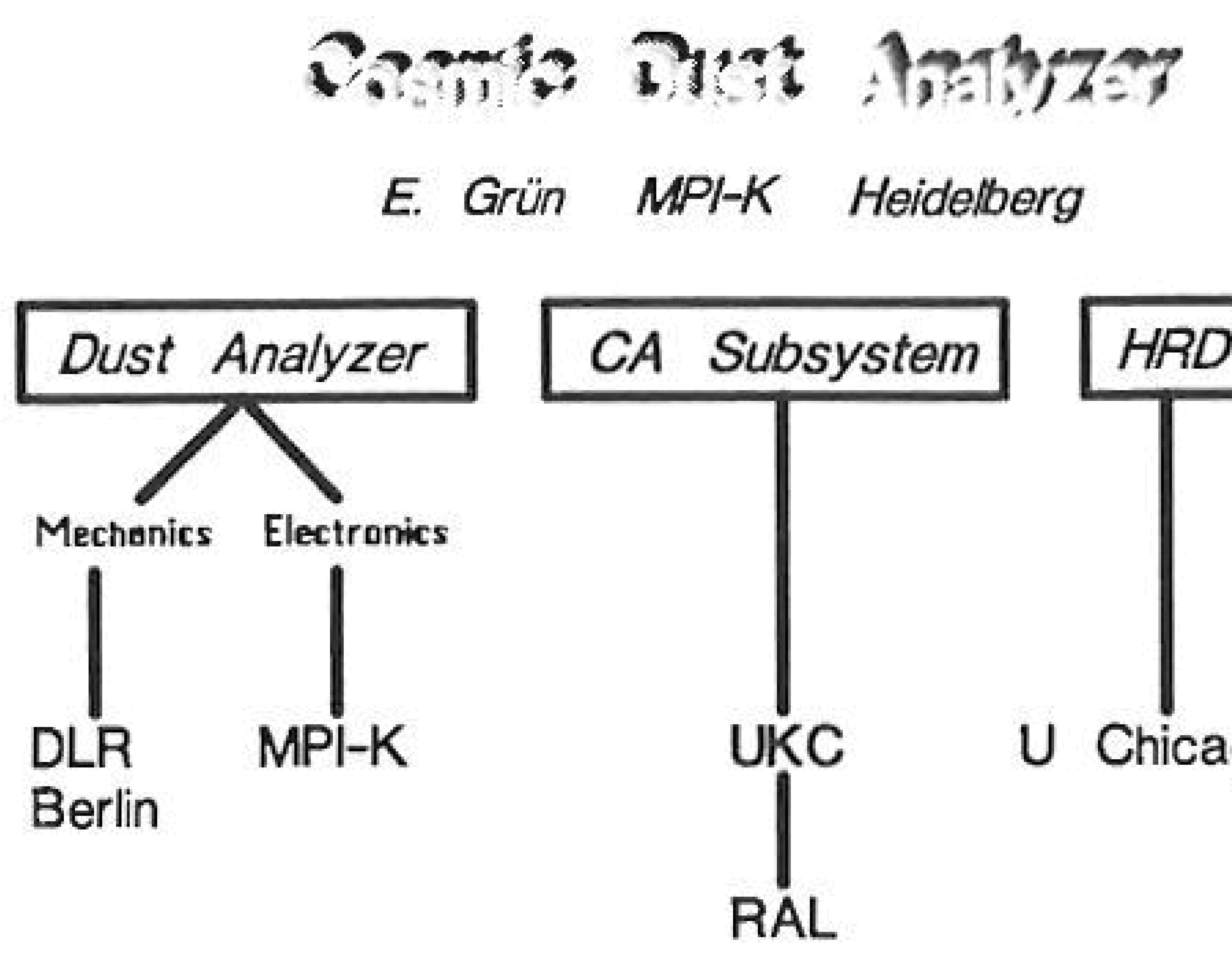

Co hvestigators

Alırens, T.J.

Auer, $S$.

Cruise, A.M.

Fechtig, H.

Havies, $O$.

Igenbergs, E.

Johnson, T.V.

Jeßberger, E.K.

Lany, P.

Lura, $\mathrm{F}$.

McDonnell, J.A.

Möhlmann, D.

Morfill, G.E.

Pernicka, E.

Schwehm, G.H.

Svestka, J.

Tuzzolino, A.J.

Wäsch, R.

Zook, HA.

Figure 1. Organization of the Cosmic Dust Analyzer project.

attached to the top of the cylindrical DA housing. The Chemical Analyzer (CA) is a subsystem of the DA and is developed by the University of Kent in Canterbury, U.K. Although the HRD is mounted on the DA, it is an independent standalone experiment built by the University of Chicago, and it is only connected by power and data lines to the DA. The HRD uses the depolarization of permantly polarized PVDF foils, whereas the DA is based on impact ionization. The DA was designed for fluxes as low as 1 impact/month, whereas the HR.D is mainly used for the times during the Saturnian ring plane crossing with high fluxes up to $10000 \mathrm{impacts} / \mathrm{s}$. Due to their different measurement principles, the DA provides more accurate dust impact parameters than the HRD. The Chemical Analyzer (CA) subsystem consists of a time-of-flight mass spectrometer providing the chemical composition of impacting dust particles. A more detailed description of the CA is given in Ratcliff et al. (1992 and 1995). This paper describes only the Dust Analyzer and the Chemical Analyzer subsystem.

\section{Dust Analyzer Functional Description and Calibration}

An electrically charged particle passing through the 2 inclined entrance grids at the front will induce charge signals at the grids (Fig. 2). The induced charge is directly proportional to the charge of the particle and allows, therefore, a determination of the electric charge of dust particles (Auer 1975). An asymmetric geometry of the entrance grids was chosen such that low-noise signals allow a measurement of the particle direction in one plane. The particle can impact either on the outer big gold plated Impact Ionization Detector (IID; QE signal) or on the small inner Chemical Analyzer Target (CAT, QC signal), which has a diameter of $16 \mathrm{~cm}$. The impact generates charged and uncharged particles 

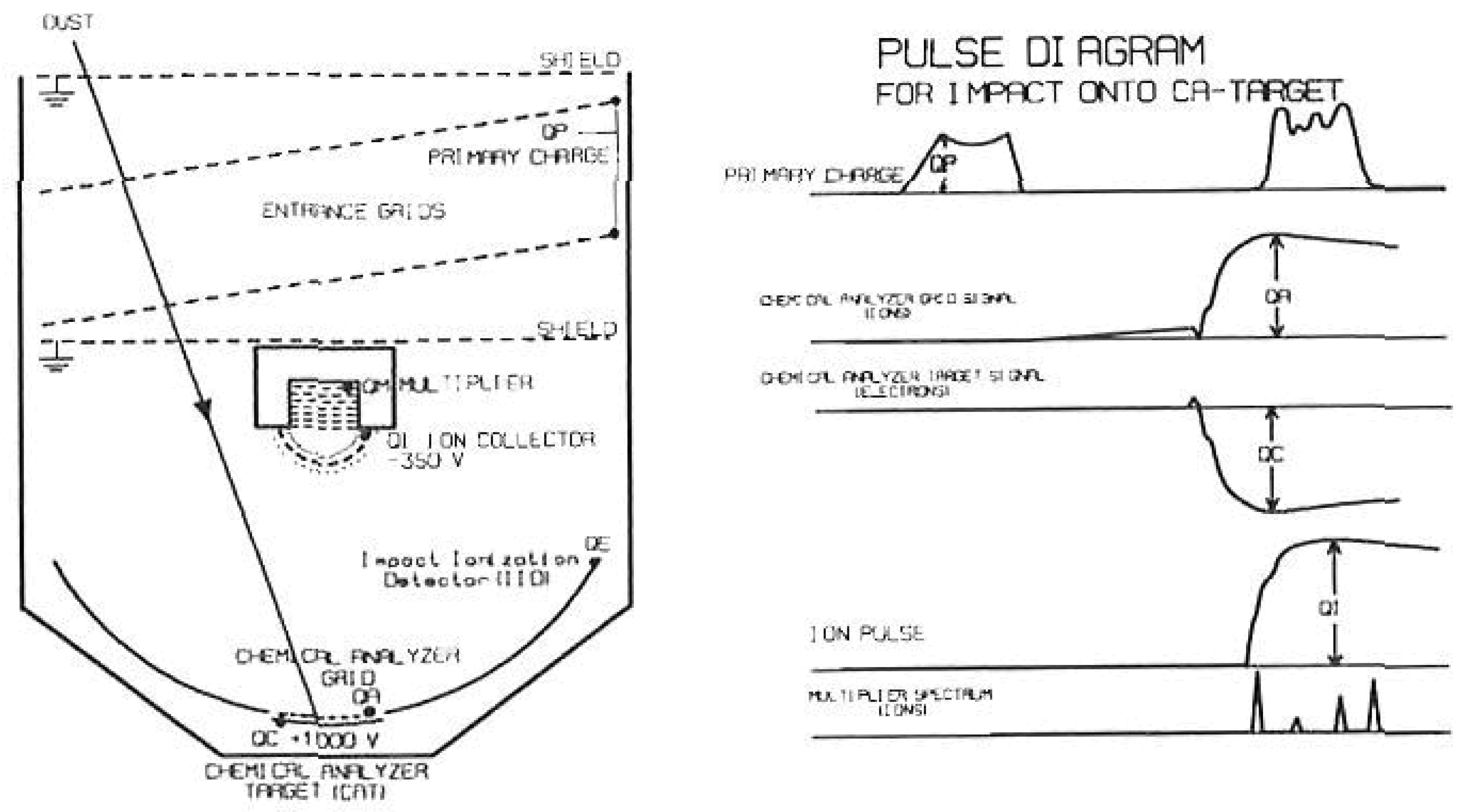

Figure 2. Schematic operation of the Cosmic Dust Analyzer with corresponding signals. The IID is gold plated.

(ejecta), atoms and ions. The electrons of this plasma are collected by the target, and the ions are accelerated towards the inner grids (ion grids, signal QI) by an applied field of $-350 \mathrm{~V}$. Some of the ions are flying through the grids producing a multiplier signal (QM).

The calibration principle of the Dust Analyzer is the same as for the former Galileo and Ulysses experiments (Göller (1988), Grün et al. (1992a), Grün et al. (1992b)). The yield of charge of the impact plasma is a function of of the dust mass and velocity. The signal risetime is mainly dependent on the impact speed. These two measurements allow the separate determination of the particle mass and speed. Typical signals observed during impacts onto the Chemical Analyzer Target (CAT) are shown in Fig. 2 and detailed in Table 1. QC represents the target signal itself, which can be devided into 3 sections: 1 ) a slowly rising induction signal which corresponds to the approaching charged particle, followed by 2) the impact plasma producing a negative charge with a fast risetime and 3 ) the slow increase up to the maximum caused by secondary charge production by late impacting ejecta particles onto other adjacent target regions. For low velocities, some material is thrown out as high speed ejecta that impact on adjacent parts of the sensor producing slow but strong charge signals. For high velocities, the particles are fully vaporized and the degree of ionization is higher caused by higher plasma temperatures. This situation leads to a fast rise of charge signals at the different channels. For medium impact velocities, a mixture of both effects is observable and the signals consist of two slopes, the fast one for the directly ionized electrons and ions, and a second one caused by secondary impacts. 


\begin{tabular}{|c|c|c|c|c|}
\hline Measurement channel & Measured quantity & $\begin{array}{l}\text { Measurement range } \\
\text { of charge and } \\
\text { risetime }\end{array}$ & Particle parameter & $\begin{array}{l}\text { Dala } \\
\text { aquisition } \\
\text { frequency } \\
\text { in } \mathrm{MHz}\end{array}$ \\
\hline $\begin{array}{l}\text { QP } \\
\text { Entrance grids }\end{array}$ & $\begin{array}{l}\text { induced charge } \\
\text { posirive } \\
\text { negative }\end{array}$ & $\begin{array}{l}10^{15}-6 \times 10^{3.1} \mathrm{C} \\
10^{15}-6 \times 10^{13} \mathrm{C} \\
\text { risetime }=0,25-80 \text { us }\end{array}$ & $\begin{array}{l}\text { Speed: } 240 \mathrm{~km} / \mathrm{s} \\
\text { Trajecrory in one plane } \\
\text { Elecuic charge: } \\
2 \times 10^{-15}-5 \times 10^{13} \mathrm{C}\end{array}$ & 6 \\
\hline $\begin{array}{l}\mathrm{QE} \quad \text { (IID) } \\
\text { Impact Ionisation Detector }\end{array}$ & $\begin{array}{l}\text { electrons (negative charge) } \\
\text { generated upon impact }\end{array}$ & $\begin{array}{l}10^{14}-10^{411} \mathrm{C} \\
\text { risetinc }=0,5-150 \text { us }\end{array}$ & $\begin{array}{l}\text { Mass: } 1 \times 10^{-5} \mathrm{~g}-1 \times 10^{7} \mathrm{~g} \\
\text { Speed: } 2-40 \mathrm{~km} / \mathrm{s}\end{array}$ & 3 \\
\hline $\begin{array}{l}\text { QC (CAT) } \\
\text { Chemucal Analyzer Target }\end{array}$ & $\uparrow$ & $\begin{array}{l}10^{14}-10^{18} \mathrm{C} \\
\text { fisetime }-0,2-10 \text { us }\end{array}$ & $\uparrow$ & 6 \\
\hline $\begin{array}{l}\mathrm{QA} \\
\text { Chemical Analyzer Grid }\end{array}$ & $\begin{array}{l}\text { lons (positive charge) } \\
\text { generated upon impact }\end{array}$ & & $\begin{array}{l}\text { - (just trigger/coincidence) } \\
\text { - not digitised }\end{array}$ & - \\
\hline $\begin{array}{l}\text { Q1 } \\
\text { Ion grid } \\
\end{array}$ & $\begin{array}{l}\text { lons (posituve charge) } \\
\text { generated upon impact }\end{array}$ & $\begin{array}{l}10^{14}-10^{5} \mathrm{C} \\
\text { risetime }=0,2-90 \text { us }\end{array}$ & $\begin{array}{l}\text { Mass } \\
\text { Speed }\end{array}$ & 6 \\
\hline $\begin{array}{l}\text { QM } \\
\text { Multiplier Dynode signal }\end{array}$ & $\begin{array}{l}\text { lons (posivive tharge) } \\
\text { generated upon impact }\end{array}$ & $\begin{array}{l}4 \times 10^{-14}=4 \times 10^{3} \quad \mathrm{C} \\
\text { (output of multiplier) } \\
\text { nsetime }=10 \mathrm{~ns}\end{array}$ & $\begin{array}{l}\text { Chemical composition } \\
\Delta \mathrm{m} / \mathrm{m}=20-40\end{array}$ & 100 \\
\hline $\begin{array}{l}\text { QM2 } \\
\text { Multiplier Anode signal }\end{array}$ & $\begin{array}{l}\text { Ions (positive charge) } \\
\text { generatcd upon impact }\end{array}$ & & $\begin{array}{l}\text {-(ust trigger/coincidence) } \\
\text { - not digitised }\end{array}$ & * \\
\hline
\end{tabular}

Table 1. Signals of the Dust Analyzer monitored by the electronics.

\section{The Chemical Analyzer Subsystem}

The grid is $3 \mathrm{~mm}$ in front of the Chemical Target and at ground potential; the Chemical Target itself is at a potential of $+1000 \mathrm{~V}$. The $1000 \mathrm{~V}$ are sufficient to separate the ions by their mass during their flight to the multiplier and, with a flight path of $230 \mathrm{~mm}$ from the target to the multiplier entry, this qualifies as a simple time-of-flight mass spectrometer (compare with Helios micrometeoroid experiment, Grün et al. 1979). Some typical spectra of preliminary laboratory measurements are shown in Fig. 3. Mass spectra were obtained for target candidate materials gold, silver, and rhodium, whereas polished and sputtered rhodium was chosen to be the optimum material for reasons of low contamination and high ion yield (Fig 3.). Clearly identified are the peaks of the target and projectile material, as well as the peaks from contaminants as carbon (12), oxygen (16), sodium (23), potassium (39), and chromium (52). For low velocity impacts, the elements sodium and potassium with their low ionization energies ( 5.1 and $4.3 \mathrm{eV}$, respectively) dominate the spectra, whereas in high velocity spectra, they play only a minor role. The mass resolution of this spectrometer is dependent on the impact location, target surface roughness, incident angle, the energy and direction distribution function of the impact plasma, and the ion mass itself. These parameters lead to complex line shapes and ongoing investigations will characterize them. A detailed discussion about impact phenomena and the shock wave propagation is given in Hornung et al. (1994) and Kinslow (1970). It is essential to optimize the mass resolution $\mathrm{m} / \Delta \mathrm{m}$ which is currently in the range between $15\left(\mathrm{H}^{+}\right)$and $50\left(\mathrm{Rh}^{+}\right)$. The mass resolution achieved so far is sufficient to determine the mineralogical class of the impacting dust by distinguishing between chondritic and iron-sulfur-nickel particles. 


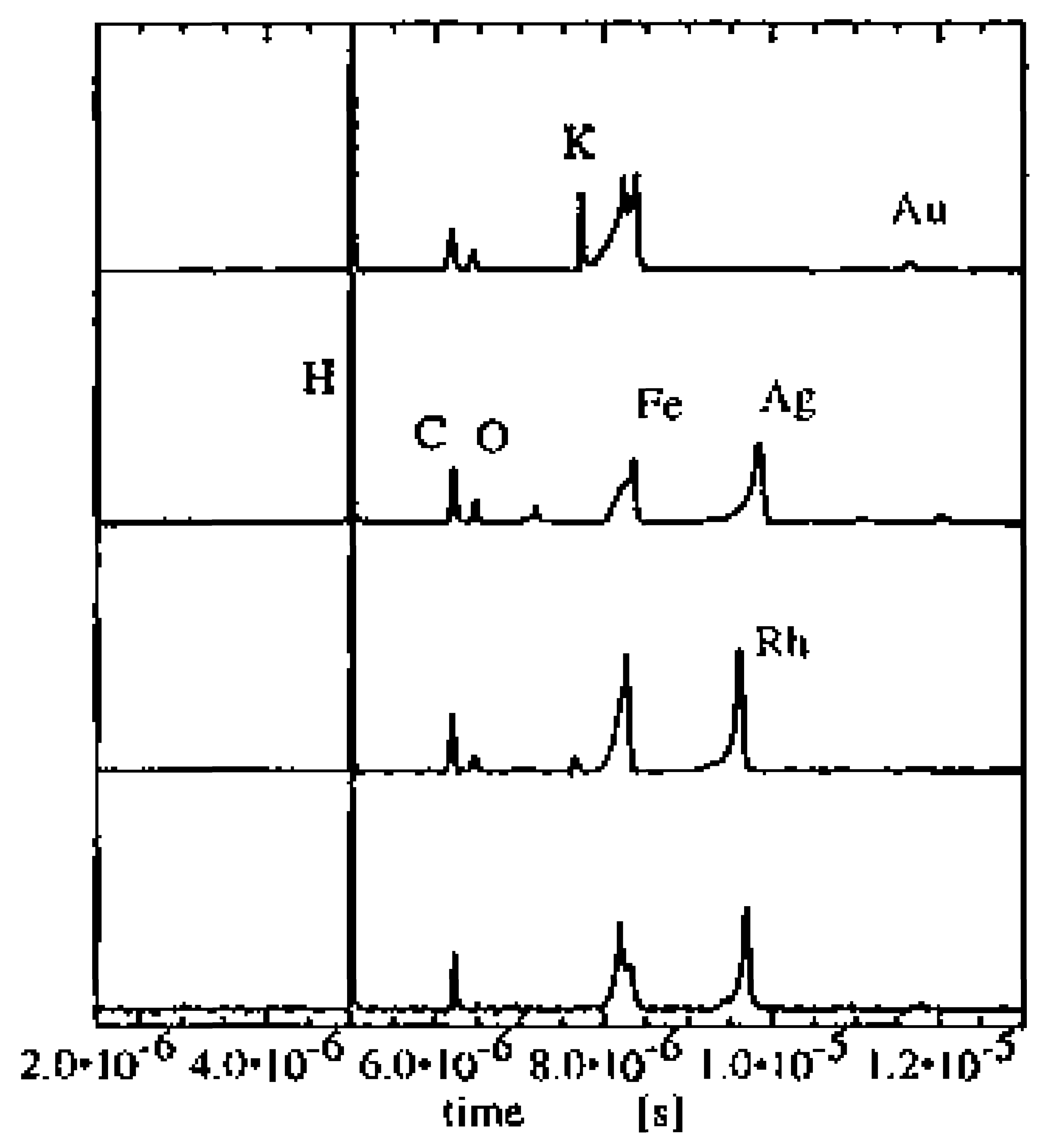

Figure 3. Mass spectra for iron particles (speed around $30 \mathrm{~km} / \mathrm{s}$, kinetic energies of $5 \cdot 10^{-9} \mathrm{~J}$ ) impacting onto gold (top), silver, polished rhodium and polished and sput tered rhodium. 'The first line represents hydrogen, the last peak belongs to the target material.

\section{Conclusion}

The Cosmic Dust Analyzer has the ability to determine the velocity ( $1-100$ $\mathrm{km} / \mathrm{s})$, mass $\left(1-10^{-15}-1 \cdot 10^{-9} \mathrm{~g}\right)$, directionality, electric charge $\left(1 \cdot 10^{-15}-1\right.$. $10^{-12} \mathrm{C}$ ) and chemical composition ( $\mathrm{m} / \Delta \mathrm{m}$ 5-50) of individual dust particles. Although the accuracy of the analyzed parameters is not greater than that of previous instruments, it is a highly sensitive and reliable design.

\section{References}

Auer, S., Rev. Sci. Instr, 46, 127-135, 1975 Göler, J. R., Dissertation, 1988, Ruprecht-Karls-Universität, Heidelberg Grün, E., Proposal Cosmic Dust Analyzer, 1989, Heidelberg

Grün, E., Fechtig, H., Gammelin, P., Kissel, J., Auer, S., Braun, G., Dalman, B.-K., Dietzel, H., Hoffmann, H.-J., BMFT-FB W 79-09, Oct. 1979 Grün, E., Fechtig, H., Giese, R.H., Kissel, J., Linkert, D., Maas, D., McDonnell, J.A.M., Morfill, G.E., Schwehm, G., Zook, H.A., 1992, Astron. Astrophys. Suppl. Ser. 92, 411-423

Grün, E., Fechtig, H., Hanner, M.S., Kisscl, J., Lindhlad, B.-A., Linkert, D., Maas, D., Morfill, G., Zook, H., 1992, Space Sci. Rev. 60, 317, 1991

Hornung, K., Kissel, J., 1994, Astron. and Astrophys., 291, 324-336 Kirslow, Ray, IIigh velocity impact phenomena, Academic Press, 1970 Ratclif, P.R., McDonnell, J.A.M., Firth, J.G., Grïn, B., 1992, J.Brit.Interpl.Soc., 45, 375380

Ratcliff, P., Gogn, $\mathrm{F}^{2}$., Grïn, B., Srama, R., 1995 COSPAR, Adv. Space Res.,

Vol. 17. 12. 111-1.15. 1996 